\title{
«The Medieval Translator - Traduire au Moyen Âge», 10, Edited by Jacqueline Jenkins and Oliver Bertrand
}

\section{Maria Colombo Timelli}

\section{(2) OpenEdition Journals \\ Édition électronique \\ URL : http://journals.openedition.org/studifrancesi/8189 \\ DOI : 10.4000/studifrancesi.8189 \\ ISSN : 2421-5856 \\ Éditeur \\ Rosenberg \& Sellier}

Édition imprimée

Date de publication : 1 mai 2009

Pagination : 152

ISSN : 0039-2944

\section{Référence électronique}

Maria Colombo Timelli, « «The Medieval Translator - Traduire au Moyen Âge», 10, Edited by Jacqueline Jenkins and Oliver Bertrand ", Studi Francesi [En ligne], 157 (LIII | I) | 2009, mis en ligne le 30 novembre 2015, consulté le 12 janvier 2021. URL : http://journals.openedition.org/studifrancesi/8189 ; DOI : https://doi.org/10.4000/studifrancesi.8189

Ce document a été généré automatiquement le 12 janvier 2021.

\section{cc) (†)}

Studi Francesi è distribuita con Licenza Creative Commons Attribuzione - Non commerciale - Non opere derivate 4.0 Internazionale. 


\title{
«The Medieval Translator - Traduire au Moyen Âge», 10, Edited by Jacqueline Jenkins and Oliver Bertrand
}

\author{
Maria Colombo Timelli
}

\section{RÉFÉRENCE}

«The Medieval Translator - Traduire au Moyen Âge», 10, Edited by Jacqueline JENKINS and Oliver BERTRAND, Turnhout, Brepols, 2007.

1 Nous signalons ici les quelques contributions concernant le xve siècle, en renvoyant le lecteur à la section Moyen Âge pour d'autres notices.

L'article de Brenda M. HOSINGTON (Henry Watson, 'Apprentyse of London' and 'Translatoure' of Romance and Satire, pp. 1-25) est consacré à la réception outre-Manche de quelques ouvrages narratifs et polémiques, traduits du français par Henry Watson et publiés par l'éditeur Wynkyn de Worde, néerlandais d'origine mais installé à Londres à partir de 1492. Il s'agit de: Valentin et Orson (1503-1505), les Evangiles des Quenouilles, la Nef des folz (1509), d'une partie d'un sermon de Saint Bernardin de Sienne (1511), Olivier de Castille (1518). Une rapide lecture des prologues et l'analyse de quelques spécimens des textes permet de reconnaitre les stratégues linguistiques, littéraires, culturelles, mises en œuvre par ce 'translateur' afin d'adapter les textes sources à un nouveau public.

Sylvie BAZIN-TACCHELLA (L'exposition du savoir chirurgical en français à la fin du Moyen Âge: les traductions françaises ( $x v^{e}$ siècle) de la 'Chirurgia Magna' de Guy de Chauliac, pp. 27-43). Ouvrage aux enjeux encyclopédiques, la Chirurgia magna de Guy de Choliac (vers 1365) a connu un succès extraordinaire dont témoignent la diffusion manuscrite (plus de trente mss. complets) et de nombreuses traductions. S.B.-T. analyse ici les caractéristiques de la traduction française $d u \mathrm{xv}^{\mathrm{e}}$ siècle, dont elle prépare l'édition 
critique: elle souligne en particulier la fidélité d'ensemble du traducteur et ses stratégies d'adaptation, la présence variable du latin dans les quatre manuscrits conservés et le traitement du lexique scientifique.

4 Véronique DUCHÉ-GAVET ( $L a$ diffusion de 'L'Histoire de Griselda' en France (XIVe-XVI siècles), pp. 193-205). Le succès de la dernière nouvelle du Decameron est depuis longtemps bien connu. V.D.-G. présente les deux premières traductions françaises (celle de Philippe de Mézières, 1384, et une version anonyme, avant 1422), pour s'arrêter plus longuement sur l'adaptation intégrée au Chevalier Errant (ms. de Paris) de Thomas de Saluces, le Roumant du Marquis de Saluces (pièce anonyme en vers composée vers 1450), le Mirouer des femmes vertueuses enfin (1547). Ces réécritures successives plient la nouvelle - et la version latine de Pétrarque - à des lectures diverses et l'adaptent à différents genres littéraires (exemplum, fabliau, leçon doctrinale).

An SMETS (Les traductions françaises et italiennes du 'De falconibus' d'Albert le Grand. Etude comparative de la structure et du lexique médical, pp. 207-221) propose une lecture comparée des quatre traductions françaises et trois italiennes du traité De falconibus (vers 1240). Sont étudiés en particulier les différences structurelles entre les versions et le traitement du lexique technique pour ce qui concerne spécialement les noms des maladies.

6 David J. WRISLEY (Translating Power and Knowledge at the Fifteenth-Century Court of Burgundy, pp. 349-363). S'interrogeant sur le concept même de "translation" à la cour de Bourgogne, D.W. discute les procédés de réécriture mis en œuvre par quelques auteurs travaillant pour Philippe le Bon ou ses proches. Dans un corpus formé de six textes traduction de l'Historia Regum Britanniae, Manekine et Girart de Roussillon de Jean Wauquelin, Mappemonde spirituelle de Jean Germain, et versions françaises de la Descriptio terre sancte et du Directorium ad passagium faciendum de Jean Miélot (ms. BnF fr. 9087) - il relève, plutôt qu'un véritable "programme" de traduction / compilation, des techniques d'adaptation culturelle, une réflexion sur le pouvoir et une actualisation menée en fonction du climat et des soucis politiques des années 1450 . 